\title{
Inflammatory Biomarkers in Chronic Obstructive Pulmonary Disease
}

\author{
Alexandra Comes, Edith Simona Ianoși, Gabriela Jimborean
}

University of Medicine and Pharmacy, Tîrgu Mureș, Romania

\section{CORRESPONDENCE \\ Edith Simona lanoși \\ Clinic of Pneumology \\ University of Medicine and Pharmacy \\ 38 Gheorghe Marinescu St \\ 540000 Tîrgu Mureș, Romania \\ Email: ianosi_edith70@yahoo.com}

\section{ARTICLE HISTORY}

Received: 25 April, 2016

Accepted: 15 May, 2016 St, 540139 Tîrgu Mureș, Romania

Gabriela Jimborean • Clinic of Pneumology, University of Medicine and Pharmacy 38 Gheorghe Marinescu St, 540000 Tîrgu Mureș, Romania

\begin{abstract}
Chronic obstructive lung disease (COPD) is a severe progressive disease associated with high morbidity and mortality. Early diagnosis and correct treatment improve the symptoms, quality of life and survival in COPD. Exacerbations of the disease are acute events that cause worsening of COPD symptoms (dyspnea, cough and/or sputum) and may require modification of stable COPD therapy. COPD exacerbations add inflammation, damage the quality of life, deteriorate the lung function, increase mortality and associate high socio-economic costs. Accurate early prediction of exacerbation and mortality risk facilitates patient selection upon risk, in order to provide appropriately targeted early treatment. The risk of having frequent exacerbations is clearly demonstrated by recognized studies in patients with specific criteria: previous exacerbation in the last year, decrease in FEV1s, increase in the score of St. George Questionnaire (life quality decline), high levels of several inflammatory biomarkers, such as neutrophils, C-reactive protein (CRP), fibrinogen, pro-calcitonin, eosinophils, IL-6, IL-8, chemokine ligand 18 (CCL-18/PARC), surfactant protein D (SP-D). Simultaneously elevated levels of CRP, fibrinogen and leukocyte count in COPD patients were associated with an increased risk for exacerbations. At the same time, elevated levels of the three biomarkers are associated with an increased risk of major comorbidities in COPD. Biomarker detection may be an additional tool for assessment and management of COPD comorbidities. Detection of pathologic levels of inflammatory biomarkers improves the ability to predict the risk mortality in COPD alongside with BODE index (BMI, obstruction in lung function, dyspnea scale, 6-minute walk test) and may provide a targeted treatment.
\end{abstract}

Keywords: inflammatory, biomarkers, COPD

\section{INTRODUCTION}

Chronic obstructive lung disease (COPD) is a progressive lung disease that includes emphysema and chronic bronchitis, characterized by pulmonary and systemic inflammation due to exposure to inhalation of pollutants: smoking, second-hand smoke, fumes, chemicals, biomass fuel, dust or toxic inorganic particles. COPD is the fourth leading cause of mortality worldwide. ${ }^{1}$ COPD is a preventable and treatable disease, for which medical specialists have to establish an early and correct diagnosis and treatment, including education for prophylaxis.

Inflammation produces bronchial narrowing with airflow limitation (by neutrophil infiltrate, fibrosis, excessive mucus production) and loss of alveolar at- 
tachments with air trapping, hyperinflation and more obstruction..$^{2,3}$ Lung triggered inflammation can pass in the systemic circulation and, alongside with chronic hypoxemia and deconditioning, can contribute to systemic complications and aggravation of comorbidities.

COPD associates several comorbidities (increased risk to lung cancer, increased cardiovascular morbidity, osteoporosis, muscle weakness, increased risk of diabetes or depression, frequent respiratory infections), poor quality of life, decrease in effort capacity, high mortality. ${ }^{1,4,5}$ Early diagnosis and correct treatment improve symptoms, the quality of life and survival.

COPD exacerbations are acute events that associate worsening of COPD symptoms (dyspnea, cough and/or sputum) and may require the modification of stable COPD therapy. ${ }^{6-8}$ COPD exacerbations damage the quality of life, bring a plus of inflammation, and decline the lung function, increase mortality and associate high socio-economic costs.

Accurate early prediction of exacerbation and mortality risk can help with patient selection upon risk and may provide appropriate early treatment initiation. ${ }^{6}$ The risk of having frequent exacerbations is clearly demonstrated by recognized studies in patients with specific criteria: previous exacerbation in the last year, decrease in FEV1s, increase in the score of St. George Questionnaire (life quality diminution), high levels of some inflammatory biomar-kers - neutrophils, C-reactive protein (CRP), fibrinogen, pro-calcitonin, eosinophils, IL-6, IL-8, chemokine ligand 18 (CCL-18/PARC), surfactant protein D (SP-D). ${ }^{9-11}$

Simultaneously, elevated levels of CRP, fibrinogen and leukocyte count in COPD patients were associated with increased risk of having exacerbations. ${ }^{12-14}$ In the same time, elevated levels of the three biomarkers are associated with an increased risk of major comorbidities in COPD. Biomarker detection may be an additional tool in risk quantification and management of COPD comorbidities. ${ }^{15-18}$ Detection of pathologic levels of inflammatory biomarkers improves the ability to predict the mortality risk in COPD alongside with the BODE index (BMI, obstruction in lung function, dyspnea scale, 6-minute walk test) and may provide a targeted treatment. ${ }^{19,20}$

\section{ROLE OF DETECTING BIOMARKERS IN COPD}

Although biomarker evaluation in COPD is particularly promising, at the moment there isn't any absolutely specific and sufficiently sensitive biomarker to predict the progression of the disease, the occurrence of exacerba- tions, the evolution under treatment or the mortality risk. ${ }^{12,14}$

Markers that have been designated as potential indicators for increased risk of developing COPD in smokers or subjects exposed to hazards and the exacerbation can be determined from different samples:

- spontaneous and induced sputum;

- condensated expiration;

- blood;

- bronchial biopsy and bronchoalveolar lavage fluid.

Elevation of the biomarkers during the COPD exacerbation and their decreasing after correct exacerbation treatment, can be quick methods for positive diagnosis of exacerbations (even mild or moderate) and an indicator for treatment efficiency.

Future studies are needed in order to validate the importance of the biomarkers in diagnosing and prognosis assessment. Furthermore, a standardized technique for biomarker evaluation is needed, as well as establishing their reference values.

\section{BLOOD BIOMARKERS IN COPD}

\section{High sensitivity C-reactive protein (CRP)}

CRP is a well-known "acute phase" inflammation marker which binds the receptors of phagocytes and plays a role in clearance of the cell with apoptosis or necrosis. ${ }^{12,21}$ CRP is synthesized in hepatocytes; its action is strongly correlated with other inflammatory mediators - IL-6, IL- $1 .{ }^{21}$ In stable COPD, an increased CRP was found to be independent from other factors such as smoking or cardiovascular damage. ${ }^{22}$

While the rise of CRP is strongly associated with COPD severity and the decline in FEV1, CRP is qualified as a promising biomarker. ${ }^{23,24} \mathrm{CRP}$ was also correlated with systemic inflammation effects: decreased energy, decreased functional capacity in patients, cardiovascular complications. ${ }^{25} \mathrm{CRP}$ is currently used as an instrument for guiding preventive therapy with statins in cardiovascular disorders. ${ }^{26}$

Elevated CRP has been linked to an increased risk of exacerbations that require hospitalization. High levels of CRP were related to increased COPD mortality, especially by lung cancer and cardiovascular complications. ${ }^{26,27}$ The highly sensitive CRP was found increased even in mild COPD before, the occurrence of muscle inflammation and muscle loss. ${ }^{28}$ Treatment with corticosteroids does not influence the decrease of CRP levels. ${ }^{29}$ 


\section{Fibrinogen}

Plasma fibrinogen is an acute phase reactant of inflammation. Numerous studies have shown that fibrinogen levels are elevated in stable COPD (even outside exacerbations) in relation to the increasing decline of FEV1 along with other biomarkers (CRP, white blood cells, TNF- $\alpha$, IL-6, IL-8). ${ }^{6,10-12,24}$

Increased fibrinogen certifies systemic inflammation in stable COPD and may partially explain some systemic side effects such as muscle wasting, osteoporosis and cardiovascular effects. $5,6,30$

The ECLIPSE study has demonstrated that an elevated fibrinogen in COPD is a predictive marker of an increased risk for exacerbations, hospitalization and mortality. ${ }^{6,31}$

\section{Neutrophils}

It is a well-known fact that inflammation in COPD is due to the growth and action of the neutrophil cells. A high level of blood neutrophils is associated with an accelerated decline in FEV1 even outside exacerbations. ${ }^{32}$ The blood neutrophil level is a predictive marker for future exacerbations (ECLIPSE study).6,33 COPD exacerbation brings more inflammation and determines the rise of blood biomarkers compared to stable COPD. ${ }^{6,12}$

Increased blood eosinophils, in COPD exacerbations, act as a sensitive indicator for systemic corticosteroid treatment introduction. Simultaneous increase of the three most relevant biomarkers (CRP, neutrophils and fibrinogen) has a strong sensibility and specificity of predicting the risk for COPD exacerbation. , $34^{6}$

\section{Procalcitonin}

Numerous studies have shown that procalcitonin levels were significantly higher during bacterial exacerbations of COPD with bacteremia. ${ }^{35-37}$ Thus, procalcitonin is a good marker for the differentiation of bacterial exacerbations from other causes, thereby contributing to the initiation of a targeted antibiotic treatment.

\section{Vascular Endothelial Growth factor (VEGF)}

VEGF has been associated with an increased deterioration of pulmonary hypertension in COPD and with an increased risk for COPD exacerbations. ${ }^{38}$

\section{Surfactant Protein D (S-PD)}

$\mathrm{S}-\mathrm{PD}$ is an "air" protein with great specificity for pathologic damage in the alveolar septa in COPD. S-PD is synthesized and secreted from type II pneumocytes and Clara cells in the bronchioles. ${ }^{39,40} \mathrm{~S}$-PD modulates the immune response (decreases the expression of pro-inflammatory cytokines, decreases lymphocytes and oxidative stress and increases phagocytosis). ${ }^{29,40}$

Recent studies have shown the importance of S-PD in antibacterial defense against pathogenic species encountered in bronchial colonization in COPD and in exacerbations: Pseudomonas aeruginosa, Klebsiella pneumoniae, Haemophilus influenzae, Streptococcus pneumoniae or Staphylococcus aureus. ${ }^{40}$

S-PD is elevated in COPD and in smokers, and is associated with an increased risk of exacerbations. Inhaled or systemic corticosteroids lower the S-PD. ${ }^{10,29,33}$

\section{Tumor necrosis factor-alpha (TNF-alpha)}

TNF-alpha mediates inflammation and is elevated in chronic stable COPD and in exacerbations. TNF-alpha has implications in muscle weakening, skeletal muscle atrophy and cachexia in advanced COPD. ${ }^{41}$

COPD is a chronic inflammation with T lymphocyte cell effectors that can induce cytotoxic LyTCD8 - via "granzyme B and perforine" (mediators of cytoplasmic granules) and epithelial cell apoptosis. T Ly percentage of intracellular granzyme B expression is increased in the blood of patients with COPD, unlike asymptomatic smokers. ${ }^{42}$

\section{Brain-type natriuretic peptide (BNP)}

BNP - a marker of cardiac suffering, was found to have high levels in patients with COPD compared with asthma patients or with controls (smokers) and was associated with an increased risk of exacerbations. ${ }^{43}$

\section{Serum troponin}

Troponin is increased in patients with COPD exacerbation, and high levels are associated with an important risk of mortality (by hypoxemia, pulmonary hypertension and acute cor pulmonale). ${ }^{19}$

\section{SPUTUM BIOMARKERS IN COPD}

Increased neutrophils in the sputum of COPD patients, is an early described phenomenon and it is determined by specific inflammation. ${ }^{44-46}$ Neutrophils are elevated in stable COPD compared to smokers and much more in exacerbations (sensitivity of $70 \%$ and specificity of $84 \%) .8,13,46$

Neutrophil elastase growth (NE) and other antimicrobial peptides correlate with the severity of COPD exacerbations. Elevation of IL-6, IL-8 and TNF-alpha mediator levels correlate with persistent symptoms in exacerbation and their decrease announces the remission period. ${ }^{11,13}$ 
Myeloperoxidase (MPO), TNF-alpha, IL-8 are associated with sputum purulence in bacterial exacerbations and high levels of WBC. 6,8

An increased number of eosinophils in the sputum can identify patients at risk for exacerbations, and patients with Asthma-COPD Overlap Syndrome (ACOS) who would benefit from early treatment with inhaled corticosteroids. ${ }^{6,47,48}$

It is well-known that VEGF has a central role in vascular remodeling in COPD (with the appearance of pulmonary arterial hypertension). VEGF was found to have an increased level in the induced sputum in COPD patients compared to non-COPD smokers or non-smokers. ${ }^{17}$

\section{MARKERS IN EXHALED AIR IN COPD EXACERBATION}

FENO - "fractional nitric oxide exhaled" in exhaled air in COPD is produced in the central and peripheral airways. FENO increase in COPD patients was higher than normal and this observation is closely related to infectious exacerbations of COPD (especially viral infections) and correlates with sputum eosinophilia and decline in FEV1. ${ }^{11}$ FENO declines along with the decrease of FEV1 during exacerbation remission. ${ }^{4} 9$

The "exhaled breath condensate" (rich in water vapors and several active molecules) has the same significance and permits the determination of a large number of cytokines (TNF-alpha, IL-6, IL-8, isoprostane, leukotrienes - moderators of inflammation and oxidative stress in COPD). ${ }^{50,51}$

\section{MARKERS IN STUDY}

Numerous ongoing studies are investigating the possible relevance of biomarkers in the early diagnosis of COPD, progression and complication assessment, but also study the benefit for targeted prevention and early treatment. ${ }^{52}$ Some markers seem to show promising results:

1. "Receptors and ligands to RAGE" ("Receptors for Advances Glycation End product") - involved in the glycation of serum lipids and proteins that alter the structure and function of endothelial/epithelial cells in COPD. ${ }^{53}$

2. "Clara cell protein" (CC16) has lower blood levels in COPD patients (current smokers or ex-smokers) than in patients without COPD. CC16 deficit would express Clara cells deficit in patients with COPD. CC16 is influenced by age and sex, but is independent of nutritional status or phenotypes (bronchitis/emphysema). ${ }^{54}$ The drop of CC16 in COPD is associated with the deficit in anti-inflammatory action and detoxifying effect of the molecule. ${ }^{55}$
3. Serum Copeptine (a vasopressin precursor) is considered to be a predictive marker for an unfavorable prognosis in COPD (independent of age, comorbidities, hypoxemia or respiratory function). Elevated Copeptine in patients with multiple exacerbations is associated in $73 \%$ of cases with an increased risk of unfavorable outcome, prolonged hospitalization, need for intensive care and increased mortality risk in the upcoming 6 months. ${ }^{56}$

4. Adiponectine - at high blood levels in COPD patients it correlates with an increased risk of disease progression and mortality. ${ }^{57}$ Adiponectine (produced in the fat tissue) grows parallel with weight loss and cachexia in advanced COPD;

5. Apolipoprotein A1 and lipocallin-1 were found in low levels in COPD compared to healthy smokers. The values correlate with disease severity and with a diminished lung function (FEV1/FVC). Considering the contribution of apolipoprotein A1 and lipocalin-1 in immune defense, their decrease may contribute to fostering infectious exacerbations. ${ }^{58}$

\section{CONCLUSION}

Inflammatory biomarker detection in COPD remains a seductive and very promising field in the near future. Some aspects of using biomarkers are still vague: standardization of indications, technique, rhythm of determination and pathological values. Numerous studies aim to identify the dynamic relationships between biomarkers and disease progression especially for treatment guiding, based on the dynamic evolution of specific markers. Future studies are considering the standardization technique for determination and interpretation. At the same time, there is an interest to increase their widespread applicability..$^{59,60}$

Evaluation of different subgroups of COPD (phenotypes) will be significantly more nuanced and easier with closer monitoring of specific markers. The use of biomarkers in COPD characterization will find its place in the guideline recommendations for disease diagnosis, prevention and treatment.

\section{CONFLICT OF INTEREST}

Nothing to declare.

\section{REFERENCES}

1. Global Strategy for the Diagnosis, Management, and Prevention of COPD 2016. Goldcopd.org.

2. Barnes PJ, Shapiro SD, Pauwels RA. Chronic obstructive pulmonary disease: molecular and cellular mechanisms. Eur Respir J. 2003;22(4):672688. 
3. Hogg JC. Pathophysiology of airflow limitation in COPD. Lancet. 2004:364:709-721.

4. Holguin F, Folch E, Redd SC, Mannino DM. Comorbidity and mortality in COPD-related hospitalizations in the United States, 1979 to 2001. Chest. 2005;128:2005-2011.

5. Garcia-Rio F, Miravitlles M, Soriano JB, et al. Systemic inflammation in chronic obstructive pulmonary disease: a population-based study. Respir Res. 2010;11:63.

6. Hurst JR, Vestbo J, Anzueto A, et al. Susceptibility to Exacerbation in COPD, ECLIPSE Investigators. N Engl J Med. 2010;363:1128-1138.

7. Hurst JR, Wedzicha JA. The biology of a chronic obstructive pulmonary disease exacerbation. Clin Chest Med. 2007;28:525-536.

8. Miravitlles M, Kruesmann F, Haverstock D, Perroncel R, Choudhri SH, Arvis P. Sputum colour and bacteria in chronic bronchitis exacerbations. Eur Respir J. 2012;39:1354-1360.

9. Liesker JJ, Bathoorn E, Postma DS et al. Sputum inflammation predicts exacerbations after cessation of inhaled corticosteroids in COPD. Respir Med. 2011;105:1853-1860.

10. Agusti A, Sin DD. Biomarkers in COPD. Clin Chest Med. 2014;35:131-141.

11. Koutsokera A, Kostikas K, Nicod LP, Fitting JW. Pulmonary biomarkers in COPD exacerbations: a systematic review. Respir Res. 2013;14:111.

12. Barnes P, Chowdhury B, Kharitonov S, et al. Pulmonary biomarkers in chronic obstructive pulmonary disease. Am J Respir Crit Care Med. 2006;174(1):6-14.

13. Sethi S, Muscarella K, Evans N, Klingman KL, Grant BJ, Murphy TF. Airway inflammation and etiology of acute exacerbations of chronic bronchitis. Chest. 2000;118:1557-1565.

14. M Cazzola, G Novelli. Biomarkers in COPD. Pulm Pharmacol Ther. 2010;23(6):493-500.

15. PM Ridker. CRP, Fibrinogen, and Cardiovascular Disease Prediction Among Those at Intermediate RiskMoving an Inflammatory Hypothesis Consensus. J Am Coll Cardiol. 2007;49(21):2129-2138.

16. Piehl-Aulin K, Jones I, Lindvall B, Magnuson A, Abdel-Halim SM. Increased serum inflammatory markers in the absence of clinical and skeletal muscle inflammation in patients with chronic obstructive pulmonary disease. Respiration. 2009;78(2):191-196.

17. Kanazawa H, Asai K, Nomura S. Vascular endothelial growth factor as a non-invasive marker of pulmonary vascular remodeling in patients with bronchitis-type of COPD. Respir Res. 2007;8(1):22.

18. Valipour A, Schreder M, Wolzt M, et al. Circulating vascular endothelial growth factor and systemic inflammatory markers in stable and exacerbated COPD. Clin Sci. 2008:115(7):225-232.

19. Brekke PH, Omland T, Holmedal SH, et al. Troponin T elevation and longterm mortality after chronic obstructive pulmonary disease exacerbation. Eur Respir J. 2008;31:563-570.

20. Celli BR, Cote CG, Marin JM, et al. The body-mass index, airflow obstruction, dyspnea and exercise capacity index in COPD. N Engl J Med. 2004;350(10):1005-12.

21. Devaraj S, Singh U, Jialal I. The evolving role of CRP in atherothrombosis. Clin Chem. 2009;55:229-238.

22. Pinto-Plata VM, Müllerova $\mathrm{H}$, Toso JF, et al. C-reactive protein in patients with COPD, control smokers and non-smokers. Thorax. 2006;61:23-28.

23. Shaaban R, Kony S, Driss F, et al. Change in Creactive protein levels and FEV1 decline: a longitudinal population-based study. Respir Med. 2006;100(12):2112-2120.

24. Donaldson GC. C-reactive Protein: does it predict mortality? Am J Respir Crit Care Med. 2007;175(3):209-210.

25. Aksu F, Çapan N, Aksu K, et al. C-reactive protein levels are raised in stable COPD patients independent of smoking behavior and biomass exposure. J Thorac Dis. 2013;5(4):414-421.

26. Higashimoto Y, Iwata T, Okada M, Satoh H, Fukuda K, Tohda Y. Serum biomarkers as predictors of lung function decline in chronic obstructive pulmonary disease. Respir Med. 2009;103(8):1231-1238.

27. Man SF, Connett JE, Anthonisen NR, et al. C-reactive protein and mortality in mild to moderate chronic obstructive pulmonary disease. Thorax. 2006;61:849-853

28. Shaker SB, von Wachenfeldt KA, Larsson S, et al. (2008), Identification of patients with COPD by measurement of plasma biomarkers. Clin Respir J. 2008;2(1):17-25.

29. Sin DD, Man SF, Marciniuk DD, et al. The effects of fluticasone with or without salmeterol on systemic biomarkers of inflammation in chronic obstructive pulmonary disease. Am J Respir Crit Care Med. 2008;177:12071214.

30. Groenewegen KH, Postma DS, Hop WC, Wielders PL, Schlösser NJ,
Wouters EF. COSMIC Study Group. Increased systemic inflammation is a risk factor for COPD exacerbations. Chest. 2008;133:350-357.

31. Dahl M, Tybjaerg-Hansen A, Vestbo J, Lange P, Nordestgaard BG. Elevated plasma fibrinogen associated with reduced pulmonary function and increased risk of chronic obstructive pulmonary disease. Am J Respir Crit Care Med. 2001;164:1008-1011.

32. Donaldson GC, Seemungal TA, Patel IS, et al. Airway and systemic inflammation and decline in lung function in COPD. Chest. 2005;128(4):1995-2004.

33. Agusti A, Calverley PM, Celli B, et al. Evaluation of COPD Longitudinally to Identify Predictive Surrogate Endpoints (ECLIPSE) investigators. Characterisation of COPD heterogeneity in the ECLIPSE cohort. Respir Res. 2010;11:122.

34. Bafadhel M, McKenna S, Terry S, et al. Blood eosinophils to direct corticosteroid treatment of exacerbations of chronic obstructive pulmonary disease. Am J Respir Crit Care Med. 2012;186:48-55.

35. Tokman S, Schuetz P, Bent S. Procalcitonin-guided antibiotic therapy for COPD exacerbations. Expert Rev Anti Infect Ther. 2011;9(6):727-735.

36. Afshari A, Harbarth S. Procalcitonin as diagnostic biomarker of sepsis. Lancet Infect Dis. 2013;13(5):382-384

37. Soreng K, Levy HR. Procalcitonin: an Emerging Biomarker of Bacterial Sepsis. Clinical Microbiology Newsletter. 2011;33(22):171-178.

38. Valipour A, Schreder M, Wolzt M, et al. Circulating vascular endothelial growth factor and systemic inflammatory markers in patients with stable and exacerbated chronic obstructive pulmonary disease. Clin Sci (Lond). 2008;115(7):225-32

39. Crouch EC. Surfactant protein-D and pulmonary host defense. Respir Res. 2000;1(2):93-108.

40. Sin DD, Pahlavan PS, Man SF. Surfactant protein D: a lung specific biomarker in COPD? Ther Adv Respir Dis. 2008;2(2):65-74.

41. 41.Vestbo J, Anderson W, Coxson $\mathrm{HO}$, et al. Evaluation of COPD longitudinally to identify predictive surrogate end-points (ECLIPSE). Eur Respir J. 2008;31:869-873.

42. Hodge S, Hodge G, Nairn J, et al. Increased airway granzyme B and perforin in current and ex-smoking COPD subjects. COPD. 2006;3(4):179187.

43. Inoue Y, Kawayama T, Iwanaga T, et al. High plasma BNP levels in stable COPD without pulmonary hypertension or Cor pulmonale. Intern Med. 2009;48:503-512.

44. Stanescu D, Sanna A, Veriter C et al. Airways obstruction, chronic expectoration and rapid decline in FEV1 in smokers are associated with increased levels of sputum neutrophils. Thorax. 1996;51(3):267-271.

45. O'Donnell R, Breen D, Wilson S, Djukanovic R. Inflammatory cells in the airways in COPD. Thorax. 2006;61(5):448-454.

46. Dragonieri S, Tongoussouva O, Zanini A, Imperatori A, Spanevello A. Markers of airway inflammation in pulmonary diseases assessed by induced sputum. Monaldi Arch Chest Dis. 2009;71(3):119-126.

47. Liesker JJ, Bathoorn E, Postma DS, Vonk JM, Timens W, Kerstjens HA. Sputum inflammation predicts exacerbations after cessation of inhaled corticosteroids in COPD. Respir Med. 2011;105(12):1853-1860.

48. Miravitlles M, Soler-Cataluna JJ, Calle M, Soriano JB. Treatment of COPD by clinical phenotypes: putting old evidence into clinical practice. Eur Respir J. 2013:41:1252-1256.

49. Antus B, Barta I, Horvath I, Csiszer E. Relationship between exhaled nitric oxide and treatment response in COPD patients with exacerbations. Respirology. 2010;15(3):472-477.

50. Koczulla AR, Noeske S, Herr C, et al. Alpha-1 antitrypsin is elevated in exhaled breath condensate and serum in exacerbated COPD patients. Respir Med. 2012;106:120-126.

51. Carpagnano GE, Resta O, Foschino-Barbaro MP, et al. Exhaled interleukine-6 and 8-isoprostane in chronic obstructive pulmonary disease: effect of carbocysteine lysine salt monohydrate (SCMC-Lys). Eur J Pharmacol. 2004;505(1-3):169-175.

52. Goh F, Shaw JG, Savarimuthu Francis SM, et al. Personalizing and targeting therapy for COPD: the role of molecular/clinical biomarkers. Expert Rev Respir Med. 2013;7(6):593-605

53. Wu L, Ma L, Nicholson LF, Black PN. Advanced glycation end product and its receptor RAGE are increased in patients with COPD. Respire Med. 2011:105(3):329-336.

54. Lomas DA, Silverman EK, Edwards LD, et al. Evaluation of serum CC-16 as a biomarker for COPD in the ECLIPSE cohort. Thorax. 2008;63:1058-1063.

55. Pilette C, Godding V, Kiss R, et al. Reduced epithelial expression of secretory component in small airways correlates with airflow obstruction in COPD. Am J Respir Crit Care Med. 2001;163:185-194. 
56. Stolz D, Christ-Crain M, Morgenthaler NG, et al. Copeptin, C-Reactive Protein, and Procalcitonin as Prognostic Biomarkers in Acute Exacerbation of COPD. Chest. 2007;131(4):1058-1067.

57. Yoon HI, Li Y, Man SF, et al. The complex relationship of serum adiponectin to COPD outcomes COPD and adiponectin. Chest. 2012;142:893-899.

58. Nicholas BL, Skipp P, Barton S, et al. Identification of lipocalin and apolipoprotein A1 as biomarkers of chronic obstructive pulmonary disease. Am J Respir Crit Care Med. 2010;181:1049-1060.

59. Stockley RA. Biomarkers in chronic obstructive pulmonary disease: confusing or useful? Int J Chron Obstruct Pulmon Dis. 2014;9:163-177.

60. Shaw JG, Vaughan A, Dent AG, et al. Biomarkers of progression of COPD. J Thorac Dis. 2014;6(11):1532-1547. 